\title{
Sequence Analysis of Rifampicin Resistance Determining Region (RRDR) of Mycobacterium tuberculosis
}

Mitesh Shrestha ${ }^{1,2}$, Hemanta Kumari Chaudhary ${ }^{1,3}$, Pradip Kumar Chaudhary ${ }^{1}$, Bal Hari Poudel ${ }^{1 *}$

\author{
${ }^{1}$ Central Department of Biotechnology, Tribhuvan University, Kathmandu, Nepal \\ ${ }^{2}$ Molecular Biotechnology Unit, Nepal Academy of Science and Technology, Patan, Nepal \\ ${ }^{3}$ Center for Molecular Dynamics Nepal, Kathmandu, Nepal
}

\begin{abstract}
Mycobacterium tuberculosis has become the cause for one of the most dreadful disease which the mankind has ever known i.e. Tuberculosis. The organism holds the ability to infect multiple organs at a time resulting in multiple symptomatic presentations in pathogenic condition while in non-pathogenic condition, it can lay dormant and remain asymptomatic. The research work presented here aimed at sequencing of Rifampicin Resistance Determining Region (RRDR) of the $r p o B$ gene present in phenotypically multidrug resistant $M$. tuberculosis. The findings showed that the major point of mutations to be present within this region was at codon 516, 526, and 531. Early diagnosis of multidrug resistance in any pathogen has become a pre - requisite for proper treatment and efficient elimination of pathogenic organisms from the host with minimal toxicity. Similarly, understanding the mutation dynamics of target genes also help in novel drug design and discovery.
\end{abstract}

Keywords: Mycobacterium tuberculosis, rifampicin, rpoB, RRDR, sequence

\section{INTRODUCTION}

Tuberculosis (TB) has a serious clinical significance as it holds the record for being a disease responsible for causing morbidity and mortality for the longest time. Nepal and the corresponding developing nations suffer most, from the brute nature of the disease [1]. The bacterium responsible, Mycobacterium tuberculosis, normally resides in the lungs causing pulmonary tuberculosis; however, it is not delimited to other organs, hence in such cases called as extra pulmonary tuberculosis [2]. The pathogen is infectious and takes aerial mode for transfer. The bacterium presents clinical symptoms based upon its location such that the pulmonary cases are recognized by chronic cough, chest pain, weight loss and others [3].

Among the distinguished members of Mycobacteria, M. tuberculosis holds a particular interest due to its clinical significance in causing various types of tuberculosis. Tuberculosis, a malady as old as human civilization itself still holds an icy grip upon its victim despite

${ }^{*}$ Corresponding author:

Bal Hari Poudel

Central Department of Biotechnology, Tribhuvan University

TU Rd, Kirtipur, Kathmandu, Nepal 44618

E-mail: balbiotech@gmail.com the advances in treatment with vaccines and antibiotics [4]. Multidrug resistant M. tuberculosis (MDR - TB) is generally referred to that strain of Mycobacterium which has become resistant to both Rifampicin and Isoniazid.

\section{Mechanism of resistance for Rifampicin}

Resistance to rifampin arises due to mutations in the $\beta$ subunit of RNA polymerase encoded by the gene $r p o B$ [5]. This includes point mutations, deletions, and insertions [6]. This results in conformational changes that determine a low affinity for the drug and consequently the development of resistance [7]. Most mutations were determined to be restricted to an 81-bp core region and are dominated by single nucleotide changes, resulting in single amino acid substitutions, although in frame deletions and insertions also occur at lower frequencies. Changes in the codons Ser531 and His526 have been documented in more than $70 \%$ of the RIFresistant isolates [8].

\section{How to cite:}

Shrestha M, Chaudhary HK, Chaudhary PK, Poudel BH (2018) Sequence Analysis of Rifampicin Resistance Determining Region (RRDR) of Mycobacterium tuberculosis. J. Trop. Life. Science 8

(1): $87-90$. 


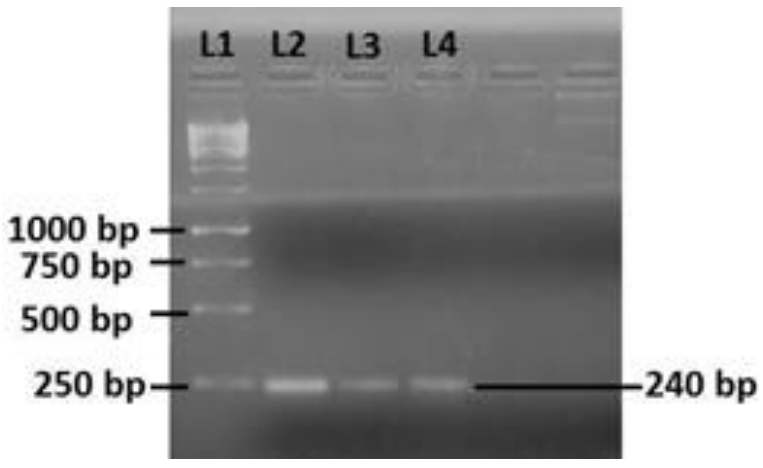

Figure 2. Agarose gel (2\%) electrophoresis for PCR products amplified using MPB64 primers for confirmation of Mycobacterium samples. L1 - Ladder; L2 - L4: Sample No. 1 to 3

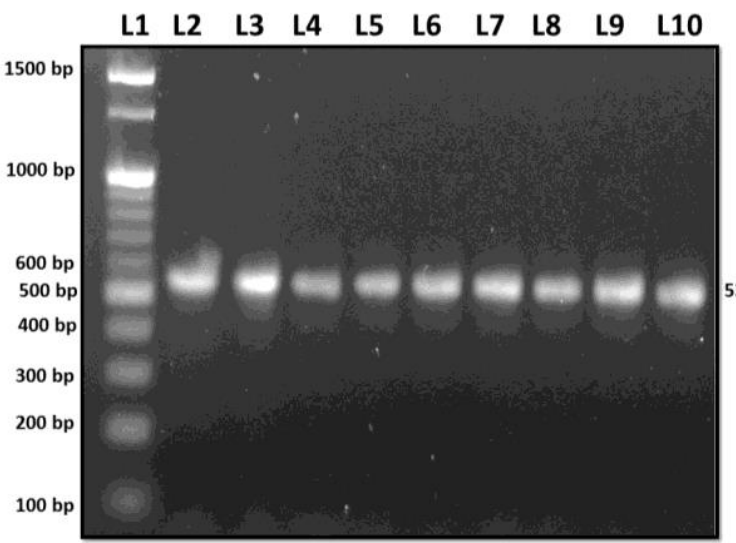

Figure 3. Agarose gel (2\%) electrophoresis for PCR products amplified using gene specific primers for RRDR region of $r p o B$. L1 - Ladder; L2 - L10: Sample No. 1 to 9.

\section{MATERIALS AND METHODS DNA preparation}

Twenty - four M. tuberculosis samples which were phenotypically determined as multiple drugs resistant by Drug Susceptibility Test were collected from Global hospital, Lalitpur, Nepal. DNA isolation from the lysate was performed using Accuprep DNA Purification Kit ${ }^{\mathrm{TM}}$.

\section{Confirmation of Mycobacterium by MPB64 Primer}

The purified DNA samples were confirmed to be that of Mycobacterium using MPB64 primers. The PCR was performed using the primer set MFP (5'-TCCGCT GCCAGTCGTCTTCC-3') and MRP (5'-GTCCTCGC GAGTCTAGGCCA-3'). The PCR condition was set as initial denaturation at $95^{\circ} \mathrm{C}$ for 5 minutes followed by denaturation at $95^{\circ} \mathrm{C}$ for 45 seconds, $55^{\circ} \mathrm{C}$ for 45 seconds and extension at $72^{\circ} \mathrm{C}$ for 30 seconds for 35 cycles followed by final extension at $72^{\circ} \mathrm{C}$ for 10 minutes and hold at $4^{\circ} \mathrm{C}$.
516

526

531

1_RPOB: CATGGACCAGAACAACCCGCTGTCGGGGTTGACCCACAAGCGCCGACTGTI'G

2_RPOB: CATGGACCAGAACAACCCGCTGTCGGGGTTGACCCACAAGCGCCGACTGTTG

3_RPOB: CATGGACCAGAACAACCCGCTGTCGGGGTTGACCGACAAGCGCCGACTGTCG

4_RPOB: CATGGACCAGAACAACCCGCTGTCGGGGTTGACCGACAAGCGCCGACTGTCG

5.RPOB: CATGGACCAGAACAACCCGCTGTCGGGGTTGACCCACAAGCGCCGACTGTIG

6_RPOB: CATGGACCAGAACAACCCGCTGTCGGGGTTGACCCACAAGCGCCGACTGTG

7_RPOB: CATGGICCAGAACAACCCGCTGTCGGGGTTGACCCACAAGCGCCGACTGTCG

8_RPOB: CATGIICCAGAACAACCCGCTGTCGGGGTTGACCCACAAGCGCCGACTGTCG

9.RPOB: CATGGACCAGAACAACCCGCTGTCGGGGTTGACCCACAAGCGCCGACTGTIG

10_RPOB: CATGGACCAGAACAACCCGCTGTCGGGGTTGACCCACAAGCGCCGACTGT G

11_RPOB: CATGGACCAGAACAACCCGCTGTCGGGGTTGACCCACAAGCGCCGACTGT G

22 RPOB: CATGGACCAGAACAACCCGCTGTCGGGGTTGACCCACAAGCGCCGACTGTIG

13_RPOB: CATGGACCAGAACAACCCGCTGTCGGGGTTGACCCACAAGCGCCGACTGTGG

14_RPOB: CATGGACCAGAACAACCCGCTGTCGGGGTTGACCGGCAAGCGCCGACTGTCG

15_RPOB: CATGGACCAGAACAACCCGCTGTCGGGGTTGACCCACAAGCGCCGACTGTIG

16 RPOB: CATGGACCAGAACAACCCGCTGTCGGGGTTGACCCACAAGCGCCGACTGTIG

17_RPOB: CATGGACCAGAACAACCCGCTGTCGGGGTTGACCCACAAGCGCCGACTGTIG

18_RPOB: CATGIACCAGAACAACCCGCTGTCGGGGTTGACCCACAAGCGCCGACTGTCG

19_RPOB: CATGGACCAGAACAACCCGCTGTCGGGGTTGACCCGCAAGCGCCGACTGTCG

127989.1: CATGGACCAGAACAACCCGCTGTCGGGGTTGACCCACAAGCGCCGACTGTCG

Figure 3. Multiple Sequence Alignment for selected region of $r p o B$ gene to display mutations in the codons 516,526 , and 531. The yellow highlighted nucleotides show the major codons that mutate while the red highlights within show changed bases when compared with the standard sequence of the strain L27989.1.

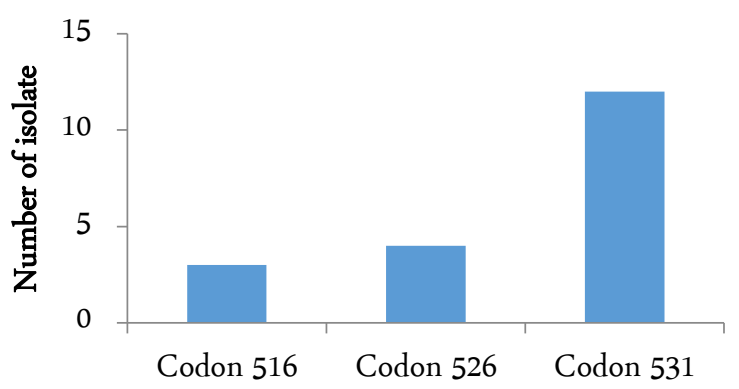

Figure 4. Graph representing the number of isolates bearing mutation at particular locus

\section{Primer for sequencing}

$r p o B$ gene specific primer was used as previously described by Fan et al. in 2003 [10]. The primer sequence covers the nucleotide sequence most prone for mutation and primarily involves the region responsible for rifampicin resistance. Hence, the region is commonly referred to as Rifampicin Resistance Determining Region (RRDR).

\section{Sequencing}

Preliminary analysis of the sequence obtained was done using Chromas Lite 2.1.1 followed by sequence alignment in the software MEGA 6.06 by Clustal W. The final sequence was then compared with the RNA polymerase $\beta$ subunit ( $r p o B$ ) gene of the $M$. tuberculosis (Accession No. L27989.1) sequence available at European Nucleotide Archive (European Molecular Biology 
Laboratory - European Bioinformatics Institute).

\section{RESULTS AND DISCUSSION}

\section{Confirmation of M. tuberculosis by PCR}

The samples obtained were confirmed as that of $M$. tuberculosis by performing PCR with MPB64 primers. The confirmation was done as evident from presence of PCR products comparative to the band of approximately $240 \mathrm{bp}$ visualized under UV as shown in Figure 1. Out of 24 samples subjected to PCR, 19 samples showed positive results. Although all 24 samples were identified as phenotypic MDR TB, the absence of bands in 5 samples could be due to loss of DNA during purification step resulting in false negative results. This is though hard to be determined as many samples despite of lacking visible band in the gel gives positive result during the PCR amplification. So, the next probable reason would be the degradation of DNA during storage causing loss of amplification. This could be due to improper storage condition. In conclusion, out of 24 samples gathered for this study, only 19 samples could be utilized for further down streaming processes.

\section{Sequence analysis}

A $537 \mathrm{bp}$ region of DNA encompassing the RRDR of $r p o B$ gene of $M$. tuberculosis was amplified using a gene specific primer which was subsequently utilized for sequencing (Figure 2). Analysis of the data obtained
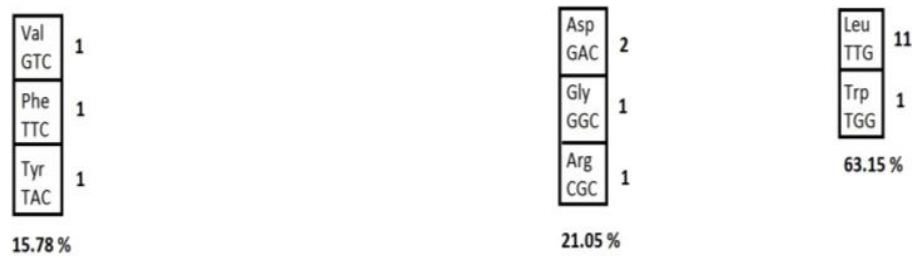

Figure 5. Schematic diagram depicting the type and number of particular mutation as well as percentage of mutation occurring at codons 516, 526, and 531 in different samples when compared to standard sequence of the strain L27989.1. [9]

Table 1. Table showing the isolates with mutation in the specific codons as validated by the sequencing. The highlighted codons represent the mutation in the codons of the sample when compared with the standard sequence of the strain L27989.1.

\begin{tabular}{|c|c|c|c|c|c|c|}
\hline Sample No. & $\begin{array}{c}\text { L27989.1 } 516 \\
\text { Codon/AA }\end{array}$ & $\begin{array}{c}\text { Sequenced } 516 \\
\text { Codon } / A A\end{array}$ & $\begin{array}{c}\text { L27989.1 } 526 \\
\text { Codon/AA }\end{array}$ & $\begin{array}{c}\text { Sequenced } 526 \\
\text { Codon } / A A\end{array}$ & $\begin{array}{c}\text { L27989.1 } 531 \\
\text { Codon/AA }\end{array}$ & $\begin{array}{c}\text { Sequenced } 531 \\
\text { Codon } / A A\end{array}$ \\
\hline $06 \mathrm{r}$ & GAC/ Asp & GAC/ Asp & $\mathrm{CAC} / \mathrm{His}$ & $\mathrm{CAC} / \mathrm{His}$ & TCG/Ser & TTG/Leu \\
\hline $07 \mathrm{r}$ & GAC/ Asp & GAC/ Asp & $\mathrm{CAC} / \mathrm{His}$ & $\mathrm{CAC} / \mathrm{His}$ & TCG/Ser & TTG/Leu \\
\hline 10r & GAC/ Asp & GAC/ Asp & $\mathrm{CAC} / \mathrm{His}$ & GAC/Asp & TCG/Ser & TCG/Ser \\
\hline $11 \mathrm{r}$ & GAC/ Asp & GAC/ Asp & $\mathrm{CAC} / \mathrm{His}$ & GAC/Asp & TCG/Ser & TCG/Ser \\
\hline $12 \mathrm{r}$ & GAC/ Asp & TAC/Tyr & $\mathrm{CAC} / \mathrm{His}$ & $\mathrm{CAC} / \mathrm{His}$ & TCG/Ser & TCG/Ser \\
\hline $14 \mathrm{r}$ & GAC/ Asp & GAC/ Asp & $\mathrm{CAC} / \mathrm{His}$ & $\mathrm{CAC} / \mathrm{His}$ & TCG/Ser & TTG/Leu \\
\hline $16 \mathrm{r}$ & GAC/ Asp & GAC/ Asp & $\mathrm{CAC} / \mathrm{His}$ & $\mathrm{CAC} / \mathrm{His}$ & TCG/Ser & TCG/Ser \\
\hline $21 \mathrm{r}$ & GAC/ Asp & GTC/Val & $\mathrm{CAC} / \mathrm{His}$ & $\mathrm{CAC} / \mathrm{His}$ & TCG/Ser & TCG/Ser \\
\hline $24 \mathrm{r}$ & GAC/ Asp & TTC/Phe & $\mathrm{CAC} / \mathrm{His}$ & $\mathrm{CAC} / \mathrm{His}$ & TCG/Ser & TCG/Ser \\
\hline $26 r$ & GAC/ Asp & GAC/ Asp & $\mathrm{CAC} / \mathrm{His}$ & $\mathrm{CAC} / \mathrm{His}$ & TCG/Ser & TTG/Leu \\
\hline $29 \mathrm{r}$ & GAC/ Asp & GAC/ Asp & $\mathrm{CAC} / \mathrm{His}$ & $\mathrm{CAC} / \mathrm{His}$ & TCG/Ser & TTG/Leu \\
\hline $31 \mathrm{r}$ & GAC/ Asp & GAC/ Asp & $\mathrm{CAC} / \mathrm{His}$ & $\mathrm{CAC} / \mathrm{His}$ & TCG/Ser & TTG/Leu \\
\hline $32 \mathrm{r}$ & GAC/ Asp & GAC/ Asp & $\mathrm{CAC} / \mathrm{His}$ & $\mathrm{CAC} / \mathrm{His}$ & TCG/Ser & TTG/Leu \\
\hline $35 r$ & GAC/ Asp & GAC/ Asp & $\mathrm{CAC} / \mathrm{His}$ & $\mathrm{CAC} / \mathrm{His}$ & TCG/Ser & TGG/Trp \\
\hline $40 \mathrm{r}$ & GAC/ Asp & GAC/ Asp & $\mathrm{CAC} / \mathrm{His}$ & GGC/Gly & TCG/Ser & TCG/Ser \\
\hline $43 r$ & GAC/ Asp & GAC/ Asp & $\mathrm{CAC} / \mathrm{His}$ & $\mathrm{CAC} / \mathrm{His}$ & TCG/Ser & TTG/Leu \\
\hline $45 r$ & GAC/ Asp & GAC/ Asp & $\mathrm{CAC} / \mathrm{His}$ & $\mathrm{CAC} / \mathrm{His}$ & TCG/Ser & TTG/Leu \\
\hline $46 r$ & GAC/ Asp & GAC/ Asp & $\mathrm{CAC} / \mathrm{His}$ & $\mathrm{CAC} / \mathrm{His}$ & TCG/Ser & TTG/Leu \\
\hline $49 \mathrm{r}$ & GAC/ Asp & GAC/ Asp & $\mathrm{CAC} / \mathrm{His}$ & CGC/Arg & TCG/Ser & TCG/Ser \\
\hline
\end{tabular}


showed at least one mutation within the region. The results obtained were comparable to that done by Fan et al., whereby the authors observed that among the samples they procured, mutation was highly probable in the codon 531 [10].

In our study, mutations could be perceived only in the codons 516, 526 and 531 with highest percentage of mutation being observed at codon $531(63.15 \%)$ followed by codon number $526(21.05 \%)$ and $516(15.78 \%)$ (Figure 3, 4, and 5). All of the mutations witnessed in this study come within the RRDR of the $r p o B$ gene as has been observed in several of the studies previously done $[11,12]$.

The RRDR is considered to be a hotspot region bearing several mutations responsible for imparting resistance to Mycobacterium against the first line of drug, Rifampicin. Although all the samples showed mutation in the region being analysed, the resistance could not be solely attributed to the analysed region only and there might be mutations on the other sites as well. The analysis of full length gene of $r p o B$ was not possible for our study; hence mutations might be present outside of the RRDR that could be contributing to varying degree of resistance against rifampicin. Further analysis of multidrug resistance $M$. tuberculosis needs to be carried to establish a correlation between the codon of mutation and the degree of resistance.

\section{CONCLUSION}

Sequence analysis of 19 samples showed mutation at three codons namely 516, 526, and 531. The mutation thus occurring possibly imparts bacterium with the ability to be resistant to the drug, rifampicin. Hence, for the timely diagnosis of the multidrug resistant Mycobacterium as well as improved prognosis for the patient, it is imperative to detect such cases at an early stage through accurate methods like sequencing.

\section{ACKNOWLEDGMENT}

The authors would like to thank Central Department of Biotechnology, Tribhuvan University for providing laboratory to perform the experiments and Global Hospital for supplying with the sample.

\section{REFERENCES}

1. Chadha VK (2009) Progress towards millennium development goals for TB control in seven Asian countries. Indian Journal of Tuberculosis 56 (8): $30-43$.

2. Farer LS, Lowell AM, Meador MP (1979) Extrapulmonary tuberculosis in the United States. American Journal of Epidemiology 109 (2): 205 - 217. doi: 10.1093/oxfordjournals. aje.a112675.

3. Zaman K (2010) Tuberculosis: A global health problem. Journal of Health, Population and Nutrition 28 (2): 111 113. doi: 10.3329/jhpn.v28i2.4879.

4. Smith I (2003) Mycobacterium tuberculosis pathogenesis and molecular determinants of virulence. Clinical Microbiology Review 16 (3): 463 - 496. doi: 10.1128/CMR.16.3.463 $-496.2003$.

5. Heep M, Rieger U, Beck D, Lehn N (2000) Mutations in the beginning of the $r p o B$ gene can induce resistance to rifamycins in both Helicobacter pylori and Mycobacterium tuberculosis. Antimicrobial Agents and Chemotherapy 44 (4): 1075 - 1077. doi: 10.1128/AAC.44.4.1075-1077.2000.

6. Ramaswamy S, Musser JM (1998) Molecular genetic basis of antimicrobial agent resistance in Mycobacterium tuberculosis. 1998 update. Tubercle and Lung Disease 79 (1): 3 - 29. doi: 10.1054/tuld.1998.0002.

7. Telenti A, Imboden P, Marchesi F et al. (1993) Direct, automated detection of rifampin-resistant Mycobacterium tuberculosis by polymerase chain reaction and single-strand conformation polymorphism analysis. Antimicrobial Agents and Chemotherapy 37 (10): 2054 - 2058. doi: 10.1128/AAC.37. 10.2054 .

8. Rattan A, Kalia A, Ahmad N (1998) Multidrug-resistant Mycobacterium tuberculosis: molecular perspectives. Emerging Infectious Diseases 4 (2): 195 - 209. doi: 10.3201/eid0402. 980207.

9. Musser JM (1995) Antimicrobial agent resistance in Mycobacteria: Molecular genetic insights. Clinical Microbiology Reviews 8 (4): 496 - 514.

10. Fan XY, Hu ZY, Xu FH et al. (2003) Rapid detection of rpoB gene mutations in Rifampin-resistant Mycobacterium tuberculosis isolated in shanghai by using the amplication refractory mutation system. Journal of Clinical Microbiology 41 (3): 993 - 997. doi: 10.1128/JCM.41.3.993-997.2003.

11. Cavusoglu C, Hilmioglu S, Guneri S, Bilgic A (2002) Characterization of $r p o B$ mutations in rifampin-resistant clinical isolates of Mycobacterium tuberculosis from Turkey by DNA sequencing and line probe assay. Journal of Clinical Microbiology 40 (12): 4435 - 4438. doi: 10.1128/JCM.40.12. 4435-4438.2002.

12. Kim BJ, Lee KH, Park BH et al. (1997) Mutations in the rpoB gene of Mycobacterium tuberculosis that interfere with PCR-Single-Strand conformation polymorphism analysis for rifampin susceptibility testing. Journal of Clinical Microbiology 35 (2): 492 - 494. doi: 10.1128/JCM.39.7.2610-2617. 2001. 